\title{
A proposta estética em Quarto de despejo, de Carolina de Jesus
}

\author{
Elzira Divina Perpétua*
}

\begin{abstract}
RESUMO
O centenário de nascimento de Carolina Maria de Jesus, comemorado em 2014, abre diversas perspectivas de estudos da obra da escritora, imortalizada em seu primeiro diário como voz coletiva da favela do Canindé nos anos 1960, de cujas páginas vemos também emergir uma personalidade singular em sua luta pessoal para manter-se íntegra e lúcida através da escrita. Ao expor o desejo da autora de se projetar longe da miséria, marcando sua diferença na escrita, Quarto de despejo compõe a poética que a consagrou e inaugura uma nova proposta estética.
\end{abstract}

Palavras-chave: Diário. Estética. Carolina de Jesus. Quarto de despejo.

Na conjunção das expressões "estética" e "escrita", a questão da literariedade se faz presente quando esta tangencia a experiência de leitura de textos que se afastam do cânone literário. A relação entre a estética e a literatura nunca foi uma questão pacífica, se contarmos que a própria demarcação do campo ficcional, não raras vezes, vai de encontro aos aspectos essenciais de algumas obras assim consideradas. Referimo-nos especificamente aos textos de cunho autobiográfico, que nos últimos anos têm sido objeto de pesquisas acadêmicas na área de Letras. Se hoje os textos confessionais são comuns no âmbito dos Estudos Culturais, fora da universidade, e mesmo entre os guardiões do academicismo, eles enfrentam limites para aceitação pela crítica. Na literatura brasileira, por exemplo, não se nega aos volumes das Memórias, de Pedro Nava, ou à Infância, de Graciliano Ramos, o pertencimento à literatura, à alta literatura, enquanto o mesmo não se aplica, pelo menos não como unanimidade, a Cidade de Deus, de Paulo Lins, ou a Quarto de despejo, de Carolina Maria de Jesus.

Como ler esses textos? Ou como dar a ler textos de cunho autobiográfico, sejam eles de autoria de escritores já consagrados, como Graciliano Ramos, ou de autores que se consagraram no mundo dos livros exatamente depois de terem seus textos publicados, como Pedro Nava, Paulo Lins, Carolina de Jesus? Tais perguntas se * Universidade Federal de Ouro Preto - UFOP. 
aplicam ao ensino da literatura, tanto nas escolas de nível fundamental, no ensino médio ou mesmo na universidade, uma vez que os estudantes não são motivados a ler textos que se configuram como escrita pessoal e raramente são motivados a produzi-los.

A tendência do senso comum até hoje continua a ser o isolamento das escritas pessoais e da literatura em dois pólos antagônicos - de um lado estaria a escrita do vivido, da realidade, cuja aproximação da veracidade seria proporcional ao afastamento do campo estético; de outro, a criação, a ficção, portanto, o trabalho de elaboração artística - aquilo que é esteticamente respeitado como arte. Vários teóricos já discorreram sobre esta falsa cisão no mundo da literatura, ao constatar quão próximos se acham os planos do vivido e da criação, da memória e da história, considerando que o escritor só pode criar no campo ficcional a partir de sua experiência, ao passo que o memorialista não deixa de adicionar o mundo ficcional à matéria rememorada. Lembramos que Roland Barthes expõe, em dois artigos de O rumor da língua (1988), aproximações entre o real e o ficcional (“O discurso da história" e “O efeito de real”), enquanto Wolgang Iser (2001), resolve o problema do binarismo real versus ficcional propondo o imaginário como terceiro elemento, o fator que medeia tanto o campo do real como o da criação.

No âmbito das escritas de cunho pessoal, há que se levar em conta, ainda, a distinção que estudiosos do gênero estabelecem entre os termos memória, autobiografia, diário, auto-retrato (e, mais recentemente a correspondência). Dentre esses, o diário comportaria um grau menos literário que os textos de memória e de autobiografia, devido ao pequeno intervalo de tempo entre o vivido e o escrito. (MIRANDA, 1992). Contudo, a questão da rememoração, comum a estas modalidades, preponderou sobre a tendência classificatória, e a crítica encontrou maneiras diversas de se referir a essas publicações, considerando serem similares as expressões escrita memorialista, escrita de cunho autobiográfico, escritas do eu, escrita de si - termos também já ressignificados quando se leva em consideração os suportes virtuais de textos e imagens. Acrescentamos a adoção, nos últimos anos, do termo "autoficção", que, embora proposto em sua especificidade por Serge Doubrovsky, conforme expõe Lejeune (2008), vem sendo usado por muitos estudiosos tanto como substituto ou sinônimo de autobiografia, como para resolver o incômodo problema do enquadramento classificatório de textos confessadamente híbridos.

Um exemplo muito interessante para o debate sobre a questão estética e a escrita autobiográfica é a obra de Carolina Maria de Jesus, em especial seus dois 
diários, Quarto de despejo e Casa de alvenaria, publicados respectivamente em 1960 e 1961, além da autobiografia póstuma Diário de Bitita (1986) e de uma edição sem cortes de parte de seus manuscritos intitulada Meu estranho diário (1996). Nos limites do presente trabalho, vamo-nos ater a relacionar Quarto de despejo: diário de uma favelada à questão estética.

Desde que foi publicado, em 1960, Quarto de despejo tem sido alvo de contestações por diferentes gerações de leitores. Nos primeiros meses de seu lançamento, o livro foi ovacionado por seu conteúdo inédito e, em especial, pela marca pessoal de que era investido: a escrita original de uma mulher, negra, de escolaridade regular mínima e moradora da favela que era exposta nas páginas do diário. Tão inusitada era a força expressiva daquele texto que, durante muito tempo, o editor dos manuscritos, o jornalista Audálio Dantas, foi acusado de ter forjado o diário. O debate em torno dos problemas levantados por Carolina de Jesus grassou rapidamente na imprensa da época, o livro recebeu quatorze traduções ainda na década de 1960, mas, em contrapartida, a leitura do diário foi proibida por pais zelosos de preservar o espírito dos filhos de conteúdo tão incendiário. Já no ano 2000 e seguintes, quando o mesmo livro foi escolhido para o vestibular em várias universidades brasileiras, novamente pais vigilantes criticaram a exigência da leitura, tanto pelo conteúdo extraliterário quanto pela linguagem do diário, que contradizia a exigência da norma padrão atinente ao concurso.

O que poucos sabem é que a questão estética foi sempre uma preocupação da própria Carolina, que possuía uma ideia bastante diferente de seu editor a respeito do diário. Para ela, o diário era pornográfico, no sentido de conter temas nada relevantes sobre a favela do Canindé - a fome, as brigas, a sujeira, o alcoolismo, o abandono social. No registro de seu cotidiano de catadora de material descartável, a trapeira fornecia um retrato daquela parte da cidade que nunca tinha sido registrado sob aquele ângulo. Para Audálio Dantas, ao contrário, era exatamente isso o que importava, porque havia no discorrer dos temas a expressão estética que causava o inesperado impacto ao leitor. E o que queria Carolina? Contrariando as expectativas de seu editor, seu desejo expresso era publicar poemas, novelas, contos - aquilo que a transportava para longe da escrita da favela. ${ }^{1}$

1 Em entrevista, Audálio Dantas, responsável por transcrever os manuscritos de Carolina de Jesus e selecionar os trechos para a publicação dos dois primeiros diários (JESUS, 1960; 1961), considera a força expressiva da escrita como fator de motivação para a editoração dos manuscritos e do esforço para a publicação do diário (Cf. PERPÉTUA, 2014). No prefácio a Casa de alvenaria, encontra-se explicitada a divergência entre o jornalista e a autora a respeito do diário e de outras modalidades de escrita que ela praticava. 


\section{Os vários eus no diário da favela}

Na presente proposta, trataremos Quarto de despejo em sua especificidade de escrita diária, com base nas disposições de Béatrice Didier (1976) a respeito do gênero, segundo quem o diário é concebido como a mais intimista forma das escritas do eu. Desenvolvido a partir de um eixo cronológico, preso ao cotidiano do escritor, o diário, não visando explicitamente à publicação, serve, dentre outros, ao objetivo de resguardar aquilo que é inconfessável para quem escreve. Devido ao fato de a distância temporal entre o vivido e seu registro pela escrita ser mínima, o teor retrospectivo também é pequeno. A perspectiva do diário é, pois, limitada pelo cotidiano do diarista. Com isso, o diário, aparentemente, oferece maior exatidão e fidelidade à experiência da realidade.

Se, por um lado, o registro imediato do vivido exige pouco do trabalho seletivo da memória, por outro, as anotações diárias vão imprimir um caráter bastante caótico à escrita, transformando o diário numa obra fragmentada, onde vários eus se evidenciam. Com isso, frustra-se o motivo que Béatrice Didier aponta como gerador de todo diário: a tentativa de negar a dispersão do eu. Como em todo texto de memória, nesse "refúgio matricial" o escritor tenta se ver como unidade. O desdobramento, porém, ocorre no próprio ato de escrever, quando o diarista é dois: aquele que viveu e aquele que escreve; e esses dois eus podem desdobrar-se, imediatamente, em muitos outros. Ao ser publicado o diário, o eu, sujeito e objeto, informe e incerto, toma consistência diante do público, reagrupando-se na unidade ilusória do escritor que assina a autoria da obra. (DIDIER, 1976, p. 116).

A submissão ao calendário, no registro dos momentos diários, permite ao diarista voltar-se sobre si enquanto escreve. Essa é uma característica que se aplica aos diários de Carolina de Jesus, notadamente aos seus manuscritos, que resguardam a intimidade de sua criadora, em trechos que foram suprimidos na publicação. ${ }^{2}$ Como consta nos prefácios de Quarto de despejo e de Casa de alvenaria, estes livros passaram por cuidadoso processo de seleção, cujo resultado foi transformar o primeiro diário em instrumento de exposição pública do dia a dia miserável de uma trapeira e da favela onde morava, enquanto o segundo diário publicado expõe o cotidiano de compromissos da autora advindos do sucesso da primeira publicação. Confiante na promessa de publicação, Carolina conta pormenores de seu cotidiano, mas também faz dos cadernos o suporte em que registra suas

2 Os microfilmes dos manuscritos encontram-se arquivados na Biblioteca Nacional, no Rio de Janeiro. Recentemente, cópia desse material foi doada à Universidade Federal de Minas Gerais, sob a custódia do Acervo de Escritores Mineiros. 
reflexões internas. Além disso, à sua escrita diária pode-se atribuir várias funções inusitadas para o gênero. Dessa forma, Carolina acaba por inovar os objetivos da narrativa diária, que será transformada em objeto de denúncia social.

Segundo Didier, o que está em cena na escrita do eu é exatamente a possibilidade de desdobramento desse eu: ao escrever, o escritor se vê como um outro, não o que viveu, mas a persona do escritor, e nessa transmutação reside o efeito catártico do diário. Em Quarto de despejo, a própria Carolina comprova o poder da escrita ao registrar: “(...) Quando fico nervosa não gosto de discutir. Prefiro escrever. Todos os dias eu escrevo. Sento no quintal e escrevo". (JESUS, 1960, p. 24). ${ }^{3}$ A vida de Carolina, transformando-se em escrita, promove o distanciamento que o relato da experiência permite ao sujeito da escrita. E mais: ao escrever o presente, com o objetivo de torná-lo público futuramente, a possibilidade de afastamento torna-se ainda mais viável, pois, projetando no futuro a sua experiência, ela adquire feições mais concretas de ficção do que de realidade.

Escrita essencialmente solitária, a produção do diário é a concretização do desejo de intimidade do escritor consigo próprio. O diário de Carolina serve, assim, como instrumento que permite o isolamento da escritora, marcando um modo de identificação, como se lê no registro: "Não gosto de ficar nas esquinas conversando. Gosto de ficar sozinha e lendo. Ou escrevendo". (JESUS, 1960, p. 26). Em Quarto de despejo, encontram-se inúmeros exemplos de como a função fundamental do diário, ainda que sendo escrito com vistas à publicação, é a de deixar aflorar o eu inconsciente que persegue uma identidade no próprio ato da escrita, permitindo à sua autora uma autoanálise. É o que ocorre especialmente no início do texto publicado, em que, juntamente com a construção de um autoconceito, nota-se a necessidade de apresentação de uma identidade moral, psicológica e social, feita de forma um tanto atabalhoada:

Estive revendo os aborrecimentos que tive esses dias (...). Suporto as contingências da vida resoluta. Eu não consegui armazenar para viver, resolvi armazenar paciência. Nunca feri ninguém. Tenho muito senso! Não quero ter processos. O meu rigistro geral é 845.936. (JESUS, 1960, p. b19).

O processo identificatório mais evidente em Quarto de despejo revela-se na auto-referência ao diário prometido à publicação, em cujos registros Carolina

3 Nas citações de Quarto de Despejo neste artigo, a ortografia e a sintaxe foram mantidas como publicadas na edição de 1960, assim como os sinais ... e (...) utilizados pelo editor para indicar supressão de trechos dos manuscritos, conforme explicitado no prefácio da edição. 
distingue-se dos outros favelados exatamente pela habilidade concedida pelo ato da escrita: “...Aqui na favela quase todos lutam com dificuldades para viver. Mas quem manifesta o que sofre é só eu e faço isto em prol dos outros." (Jesus, 1960, p. 36). Ao escrever sobre vizinhos do Canindé, raramente Carolina cita-se a si mesma diretamente; favelados são os outros "em prol" de quem escreve (e, acrescentamos, de cujas histórias ela se serve como parte do lixo que alimenta sua escrita): "Escrevo sobre todas as lambanças que pratica os favelados, estes projetos de gente humana." (JESUS, 1960, p. 24).

Ao utilizar expressões depreciativas para se referir aos vizinhos, Carolina expõe um ponto de vista em relação ao objeto de sua escrita e, por conseqüência, ao gênero em que o faz. Nesse sentido, aos próprios olhos, Carolina não é um projeto, mas uma escritora já feita. Mesmo porque, além de escrever o diário, concebia projetos individuais, como lemos nos registros em que ela manifesta, nos cadernos, o desejo de ver publicada sua escrita ficcional e poética. Por outro lado, a editoração de Quarto de despejo mostra-nos que a autora constitui um projeto que se realiza, à medida que se destaca do meio em que vive, por intermédio da escrita, e se concretiza, no final, quando fechamos o livro. Mas, nessa travessia, vemos que a distinção que faz de si por meio da escrita corresponde, na opinião de sua comunidade, a uma desqualificação: É o que percebemos, entre inúmeros, no seguinte registro: “...Sentei ao sol para escrever. A filha da Silvia, uma menina de 6 anos, passava e dizia: - Está escrevendo, negra fedida? A mãe ouvia e não repreendia. São as mães que instigam.” (JESUS, 1960, p. 28).

Se o diarista é, por sua condição, duplo personagem, o diário de Carolina nos mostra, em suas divergências com os vizinhos, a evidência da observação de Béatrice Didier de que, no desdobramento do sujeito, aquele que escreve é sempre superior em relação àquele que viveu. Fiel ao seu isolamento, indiferente às provocações dos vizinhos, Carolina parece encontrar na letra o prazer e transforma o livro num objeto de desejo: "Quando cheguei em casa era 22,30. Liguei o radio. Tomei banho. Esquentei comida. Li um pouco. Não sei dormir sem ler. Gosto de manusear um livro. O livro é a melhor invenção do homem." (JESUS, 1960, p. 26). Inusitadas declarações de amor ao livro vão-se sucedendo, sob variadas formas, ao longo do diário. Até mesmo o motivo de sua recusa em aceitar as propostas de casamento deve-se, antes de qualquer conjectura de ordem sentimental, a uma opção intencional em favor da escrita.

$\mathrm{O}$ fato de a escrita do diário ser marcada cronologicamente permite à identidade de todo diarista revelar-se de forma fragmentada. Contudo, quando o diário é publicado, a seleção dos manuscritos acentua o estilhaçamento desse retrato. Em 
Quarto de despejo, o caráter fragmentado do retrato permanece, apesar de o editor ter desejado compô-lo por um ângulo único. Fragmentado como o diário, o esboço de Carolina no livro publicado apenas fulgura, aos saltos, para ser apagado em seguida e, imediatamente depois, ceder lugar a uma nova imagem, que, como as outras, nunca é captada inteiramente. Ao final da leitura do diário, percebemos que a escritora tenta fazer de si, ou o editor tentou fazer dela, um retrato em relação ao Outro, identificando-se, ainda que de modo desorganizado, a ela mesma, não por meio de traços próprios, mas pelo traço da escrita que a distingue dos iletrados.

Embora na maioria das vezes a autora se coloque numa posição distinta em relação aos vizinhos, seja pelo devaneio, seja pela negativa contundente da perenidade da miséria, em alguns momentos sua identificação se dá por um processo de espelhamento de si própria nos vizinhos de quem quer se manter distante. Em fins de maio de 1958, por exemplo, Carolina se refere a uma nova moradora na favela como "companheira de infortúnio" que "olhava a favela, suas lamas e suas crianças paupérrimas", como um reflexo no espelho: "Foi o olhar mais triste que já presenciei." (JESUS, 1960, p. 47). Em 15 de junho daquele mesmo ano, ao saber do suicídio de uma desconhecida após tríplice infanticídio, "por encontrar dificuldade de viver", mais uma vez, a diarista registra a experiência do processo identificatório: “...A noticia do jornal deixou-me nervosa. Passei o dia chingando os politicos, porque eu também quando não tenho nada para dar aos meus filhos fico quase louca." (JESUS, 1960, p. 63).

Ocorre também a negação de Carolina em relação à própria imagem devolvida pelo espelho, que lhe parece um rastro do que ela foi, ou uma figura sobrenatural que se desvanece com a realidade, fruto da dificuldade de sobrevivência, que ela recusa admitir: “....Já emagreci 8 quilos. Eu não tenho carne, e o pouco que tenho desaparece. Peguei os papeis e saí. Quando passei diante de uma vitrine vi o meu reflexo. Desviei o olhar, porque tinha a impressão de estar vendo um fantasma." (JESUS, 1960, p. 173). Por outro lado, cada registro vai revelando o horror da escritora em entregar-se à favela, onde se sente "um objeto fora de uso, digna de estar num quarto de despejo." (JESUS, 1960, p. 37). Na verdade, a persistência da escrita de Carolina associa seu traço mais a um caráter de desejo que de despejo.

Carolina de Jesus tece muitas reflexões interessantes a partir do ato de registrar literalmente o seu dia-a-dia de catadora. Mesmo sendo um trabalho que lhe proporciona apenas uma condição mínima de sobrevivência, ele só pode ser efetivado se executado pacientemente, dia após dia, reservando para o dia seguinte o enigma da dúvida. Mas o dejeto da grande cidade vai proporcionar, especialmente a ela, dois tipos de alimento. Com o pouco dinheiro arrecadado pela venda do 
lixo, ela compra os gêneros com que sobrevive. É o lixo que lhe fornece também o suporte da inscrição de sua escrita, os cadernos semiusados, além de ser seu tema constante. Carolina revira o lixo para tentar aproveitar restos de alimentos. Metaforicamente, é esse mesmo resíduo que lhe dá o alimento intelectual. Suas anotações, embora presas ao calendário civil, possuem um ritmo especial, marcado pelos dias de maior abundância ou de falta de lixo, o que lhe permite traçar um calendário semanal específico: no sábado é necessário ajuntar o proporcional à alimentação por dois dias; a segunda-feira é dia de menos penúria, dia de muito papel nas ruas.

O ritmo incessante da narrativa diária, em que se repetem com palavras os atos repetidos do dia que passou - sempre igual, na miséria, ao anterior - constitui a tônica dos registros selecionados, que, não fosse pelo seu conteúdo medonho e às vezes lúgubre, cederia lugar ao fastio e ao tédio. Esse modo de tentar catar/contar de forma diferente o que é sempre igual dá a Carolina a exata medida para a seguinte reflexão determinista: "Parece que eu vim ao mundo predestinada a catar. Só não cato a felicidade.” (JESUS, 1960, p. 81). Essa impressão já havia sido apontada por ela como determinação de uma força superior, o fatum das tragédias: "Parece que quando eu nasci o destino marcou-me para passar fome." (JESUS, 1960, p. 45).

Assim inserida na miséria plena, parece aceitável que as observações da escritora sobre sua vida acabem por cair numa espécie de fatalismo. Entretanto, apesar de registrar possibilidades drásticas como solução para a desesperança, Carolina parte para um experimento diferente dos outros miseráveis, seguindo a sua intuição e o desejo, selecionando restos do lixo e das palavras como forma de saciar a fome: "Eu cato papel, ferro, e nas horas vagas escrevo." (JESUS, 1960, p. 102).

A descrição da penúria diária também cede lugar a devaneios, assim como a reflexões sobre a realidade e a busca de resposta para suas angústias. Vemos pelo diário que o refúgio representado pela escrita está associado também ao sentimento de rejeição social com que convive diariamente, cuja violência expulsa-a do convívio humano. Seu olhar passeia muitas vezes cansado daquela paisagem familiar de misérias, mas sua perspicácia permite-lhe realizar uma operação mental utilizando-se de um jogo de palavras que terminam por situar com precisão vocabular a situação social dos favelados:

"Nós somos pobres, viemos para as margens do rio. As margens do rio são os lugares do lixo e dos marginais. Gente da favela é considerada marginais. Não mais se vê os corvos voando as margens do rio, perto dos lixos. Os homens desempregados substituiram os corvos." (JESUS, 1960, p. 55). 
A favela do Canindé, situada às margens do Rio Tietê, afigura-se-lhe não apenas como a morada dos marginalizados pela miséria, mas também como o refúgio da marginália, dos que vivem à margem da lei. $\mathrm{E}$, apesar da visão para além de si, a escritora acaba por se incluir entre os marginalizados, ela própria desterritorializada espacial e socialmente onde vive.

Em vez de traçar diretamente o seu perfil, contudo, Carolina admite apenas querer esboçar o dia a dia daquela coletividade marginal em todos os aspectos. Mas, ao falar do Canindé como simples observadora, ela também fala de si mesma, tanto em relação ao microcosmo representado pelos vizinhos, quanto ao macrocosmo social e anônimo, representado, por sua vez, pela figura de alguns homens públicos e pela sociedade em geral. Ao volver o seu olhar para fora de si, Carolina vê o seu reflexo, o que a obriga a proferir seu próprio veredito, como se lê no registro:

\begin{abstract}
Abri a janela e vi as mulheres que passam rapidas com seus agasalhos descorados e gastos pelo tempo. Daqui a uns tempos estes palitol que elas ganharam de outros e que de há muito devia estar num museu, vão ser substituidos por outros. É os politicos que há de nos dar. Devo incluir-me, porque eu tambem sou favelada. Sou rebotalho. Estou no quarto de despejo, e o que está no quarto de despejo ou queima-se ou joga-se no lixo. (JESUS, 1960, p. 38).
\end{abstract}

Assim, tendo o contexto sociogeográfico como paisagem, Carolina olha para si e para os outros eus que consigo interagem. Nos textos selecionados para publicação, vemos que Carolina, mergulhada numa escrita tradicionalmente subjetiva, consegue esboçar objetivamente os traços do Canindé, mesmo quando nela se inclui, vendo-se personagem de si mesma. Dessa forma, ao pretender narrar a vida daquela comunidade, vemos em Quarto de despejo que a autora situa-se ora como mera testemunha que registra um documento da favela, ora como personagem e modelo dos dramas que se desenvolvem diariamente a seus olhos. Ante a letargia dos favelados que se calam e a indiferença generalizada, que determina a banalização da miséria, o caderno onde escreve é, para a autora, a ponte entre duas extremidades: "Eu escrevo porque preciso mostrar aos politicos as pessimas qualidades de vocês." (JESUS, 1960, p. 164).

Algumas vezes, não se contentando apenas em narrar as agruras dos miseráveis, ela assume, de forma ostensiva e ousada, a função de porta-voz dos favelados diante de personalidades públicas. Ao fazê-lo, às vezes utiliza inesperados recursos literários, como no exemplo abaixo, em que recorre à linguagem metafórica como modo de fazer passar uma ameaça velada: 
O que o senhor Juscelino tem de aproveitável é a voz. Parece um sabiá e a sua voz é agradável aos ouvidos. [...] Cuidado sabiá, para não perder esta gaiola, porque os gatos quando estão com fome contempla as aves nas gaiolas. E os favelados são os gatos. Tem fome. (JESUS, 1960, p. 35).

O relato diário vai proporcionar ao leitor uma visão da favela em seus aspectos mais cruéis. É a figura da autora de Quarto de despejo, entretanto, que vai sobrepor-se à miséria relatada, como quer Carolina, que nitidamente se destaca do meio favelado por meio de sua arte:

Tem pessoas aqui na favela que diz que eu quero ser muita coisa porque não bebo pinga. Eu sou sozinha. Tenho três filhos. Se eu viciar no alcool os meus filhos não irá respeitar-me. Escrevendo isto estou cometendo uma tolice. Eu não tenho que dar satisfações a ninguem. Para concluir, eu não bebo porque não gosto, e acabou-se. Eu prefiro empregar o meu dinheiro em livros do que no alcool. Se você achar que eu estou agindo acertadamente, peço-te para dizer: - Muito bem, Carolina! (JESUS, 1960, p.73).

Vemos nesse exemplo que Carolina se projeta como intelectual, distinguindose dos vizinhos do Canindé e por esta opção espera receber aprovação de seu leitor. Do ponto de vista da especificidade deste diário pode-se inferir que, se em suas páginas repercute uma representatividade coletiva, que outorga ao diário uma função social e dá a ver a miséria do Canindé, sobressai dessa mesma coletividade o gesto solitário de Carolina, para quem escrever funciona menos como ato de catarse do que como forma de resistir à miséria.

Por fim, convém lembrar que esta é uma forma de luta também marginal, já que, embora utilizando o código linguístico comum, sua escrita remete continuamente, em forma, tanto quanto em conteúdo, ao seu lugar de origem, destoando de outras publicações pessoais que não levantam dúvidas sobre o espaço que ocupam no mundo da leitura literária. Malogrado o desejo da escritora de ter seus textos ficcionais e poéticos publicados em vida, é a poética do diário, que inaugura uma estética desconhecida até então, a responsável por projetar hoje o nome de Carolina de Jesus no mundo das letras. 


\begin{abstract}
The birth centenary of Carolina Maria de Jesus, celebrated in 2014, opens several perspectives for studies by the writer's work, immortalized in his first diary as the collective voice of the Canindé slum in 1960s. In these pages she also emerges as a singular personality in her personal struggle to keep herself honest and lucid through writing. By exposing the desire to project herself away from misery, marking their difference through writing, Quarto de despejo composes the poetic that has made her famous and introduces a new aesthetic proposal.
\end{abstract}

Key words: Diary. Aesthetics. Carolina de Jesus. Quarto de despejo.

Referências

BARTHES, Roland. O rumor da língua. Trad. Mário Laranjeira. São Paulo: Brasiliense, 1988.

DIDIER, Béatrice. Le journal intime. Paris: PUF, 1976.

ISER, Wolfgang. Os atos de fingir ou o que é fictício no texto ficcional. In: LIMA, Luiz Costa. Teoria da literatura em suas fontes. Rio de Janeiro: Civilização Brasileira, 2001, p. 955-987.

JESUS, Carolina Maria de. Quarto de despejo: diário de uma favelada. São Paulo: Francisco Alves, 1960.

JESUS, Carolina Maria de. Casa de alvenaria: diário de uma ex-favelada. São Paulo: Francisco Alves, 1961.

JESUS, Carolina Maria de. Diário de Bitita. Rio de Janeiro: Nova Fronteira, 1986.

JESUS, Carolina Maria de. Meu estranho diário. São Paulo: Xamã, 1996. (Organizado por José Carlos Sebe Bom Meihy e Robert M. Levine).

LEJEUNE, P. O pacto autobiográfico. Trad. J. M. G. Noronha; M. I. C. Guedes. Belo Horizonte: Ed. UFMG, 2008.

MIRANDA, Wander Melo. Corpos escritos: Graciliano Ramos e Silviano Santiago. São Paulo: Editora da Universidade de São Paulo; Belo Horizonte: Editora UFMG, 1992. 
PERPÉTUA, Elzira Divina. A vida escrita de Carolina Maria de Jesus. Belo Horizonte: Nandyala, 2014. 